\title{
Three-dimensional $\mathrm{Ni}_{3} \mathrm{Sn}_{4}$ Negative Electrodes for Lithium-Ion Batteries
}

\author{
Arailym Nurpeissova ${ }^{1,2, *}$, Akylbek Adi ${ }^{1,2}$, Assylzat Aishova ${ }^{1,2}$, Aliya Mukanova ${ }^{1,3}$, Sung-Soo Kim ${ }^{4}$, \\ Zhumabay Bakenov ${ }^{1,2,3}$ \\ ${ }^{1}$ National Laboratory Astana, 53 Kabanbay Batyr Ave., Astana 010000, Kazakhstan \\ ${ }^{2}$ Institute of Batteries, Block 13, 53 Kabanbay Batyr Ave., Astana 010000, Kazakhstan \\ ${ }^{3}$ School of Engineering, Nazarbayev University, 53 Kabanbay Batyr Ave., Astana 010000, \\ Kazakhstan \\ ${ }^{4}$ Graduate School of Energy Science and Technology, Chungnam National University, 99 Daehak \\ ave., Yuseong-gu, Daejeon 34134, Republic of Korea \\ *E-mail: arailym.nurpeissova@ nu.edu.kz
}

doi: $10.20964 / 2018.07 .75$

Received: 9 March 2018 / Accepted: 10 May 2018 / Published: 5 June 2018

\begin{abstract}
Three-dimensional alloy based $\mathrm{Ni}_{3} \mathrm{Sn}_{4}$ negative electrodes were fabricated by simple electrodeposition technique on a mesoporous nickel foam substrate to improve the capacity and cyclability of $\mathrm{Ni}_{3} \mathrm{Sn}_{4}$ anodes for lithium-ion batteries. The combination of thin film geometry with three-dimensional foam structure is aimed to optimize the ionic/electronic current paths, and to accommodate the mechanical stresses induced by the volume changes in the electrode during repeated cycling. The surface morphology of the obtained $\mathrm{Ni}_{3} \mathrm{Sn}_{4}$ alloy electrodes was characterized by scanning electron microscopy coupled with energy-dispersive X-ray spectroscopy. X-ray diffraction analysis was performed to characterize the phases and possible impurities present in the alloy. The electrochemical features of the electrodes were investigated by cyclic voltammetry and galvanostatic charge-discharge test experiments. Obtained results showed that the as-prepared three-dimensional $\mathrm{Ni}_{3} \mathrm{Sn}_{4}$ anodes are capable of providing satisfactory lithium storage and promising cycling performance.
\end{abstract}

Keywords: Three-dimensional anode; electrodeposition; $\mathrm{Ni}_{3} \mathrm{Sn}_{4}$ alloy; lithium-ion battery

\section{$\underline{\text { FULL TEXT }}$}

(C) 2018 The Authors. Published by ESG (www.electrochemsci.org). This article is an open access article distributed under the terms and conditions of the Creative Commons Attribution license (http://creativecommons.org/licenses/by/4.0/). 